Rev. Roum. Chim.,
ACADEMIA ROMÂNĂ
Revue Roumaine de Chimie
http://web.icf.ro/rrch/

\title{
EXPERIMENTAL EVALUTION OF FREE CHLORINE ADSORPTION FROM CIRCULATING WATER IN COOLING TOWERS BY ACTIVATED CARBON IN A FIXED BED COLUMN
}

\author{
Bahman BEHZADI, ${ }^{\mathrm{a}}$ Maziar NOEI, ${ }^{\mathrm{b}}$ Alireza AZIMI,,${ }^{\mathrm{a},}{ }^{,}$Masoumeh MIRZAEI ${ }^{\mathrm{a}}$ \\ and Hossein ANARAKI-ARDAKANI ${ }^{\mathrm{a}}$ \\ ${ }^{a}$ Department of Chemical Engineering, Mahshahr Branch, Islamic Azad University, Mahshahr, Iran \\ ${ }^{\mathrm{b}}$ Department of Chemistry, Mahshahr Branch, Islamic Azad University, Mahshahr, Iran
}

\begin{abstract}
One of the most important absorbents used in the water and sewage industry and oil and gas industry is the activated carbon, which can be used to remove free chlorine from water and wastewater. If the important parameters of the process affecting the adsorption efficiency are not recognized and controlled, it can cause irreparable damage to downstream equipment and the environment. In the cooling towers system, excessive amounts of chlorine are often injected into the system, which can cause severe corrosion of the equipment and stop production. In this study, the removal of free chlorine from the circulating water of the cooling tower was examined by adsorption and in order to evaluate the effect of $\mathrm{pH}$ and water flow containing free chlorine and concentration in the inlet water, experiments were performed on a pilot scale. The adsorbent used in this research was PICA's Industrial Carbon Active. For this purpose, a tower with a fixed bed was first designed and built. The tower used 4,500 grams of activated carbon as an adsorbent. Experimental results showed that by passing 51549 liters of chlorinated water with free chlorine (at different concentrations and $\mathrm{pH}$ ), $4058 \mathrm{~g}$ of chlorine was absorbed by activated carbon. Experimental results also showed that the lower the $\mathrm{pH}$ of the solution and the higher the flow rate of the solution, the higher the amount of chlorine adsorption by activated carbon. Also in this study, kinetic reaction of chlorine adsorption by activated carbon was investigated with Thomas, Adams - Bohart, and YoonNelson Models, and the reaction rate constant $\mathrm{K}$ for the Thomas and Adams - Bohart models was $\mathrm{K}_{\mathrm{b}}=\mathrm{K}_{\mathrm{Th}}=0.02037037 \mathrm{~min}^{-1}$ $\left(\mathrm{R}^{2}=0.915\right)$, and for the kinetic models of Wang and Yoon - Nelson, $\mathrm{K}_{\mathrm{W}}=\mathrm{K}_{\mathrm{YN}}=0.022 \mathrm{~min}^{-1}$ was obtained and the time required to consume $50 \%$ of the adsorption bed was $\mathrm{t}^{1 / 2}=258.09 \mathrm{~min}$. The Wolburska kinetic model did not match well with the experimental data $\left(\mathrm{R}^{2}=0.769\right)$.
\end{abstract}

\section{INTRODUCTION}

The petrochemical industry of the world and Iran suffers a lot every year in terms of operating and maintaining cooling towers. Microbial corrosion is one of the most common corrosions in the industry. One of the most important and common disinfectants used is chlorine gas and its derivatives. In large industrial units, experience has shown that in addition to environmental pollution, failure to control the amount of active chlorine has caused corrosion of equipment, including heat exchangers, and has stopped production. Cooling towers are one of the most important parts of the

\footnotetext{
${ }^{*}$ Corresponding author: alireza_azimi550@yahoo.com
} 
petrochemical industry and it is not possible to produce and continue production without cooling towers. Pollution and water loss in cooling towers have always been a major concern for researchers and industrialists. A number of methods such as electrochemical method, Bio adsorption, Calcined Layer Double Hydroxides (CLDH) method, have been used for the removal of chlorine from polluted water. One of the most important adsorbents in the oil, gas and petrochemical industry is industrial activated carbon. One of the uses of this material is to absorb chlorine gas in the process. In this study, it has been tried to remove excess chlorine in the circulating water of the cooling towers using activated carbon and also the effect of $\mathrm{pH}$ (alkalinity or acidity) of substances and system temperature on free chlorine uptake by activated carbon was investigated.

Today, activated carbon is widely used in industry, including reducing the load of microbial contamination and reducing the chemical oxygen demand of BOD (Biochemical oxygen demand), $\mathrm{COD}$, water and wastewater. ${ }^{1,2}$ Activated carbon in has been used in dechlorination, and water and wastewater have been used in debromination. ${ }^{3}$ Lakshmanan et al. used activated carbon to remove free chlorine and chlorate. ${ }^{4}$ BOD measures the amount of oxygen required by the aerobic organisms to decompose organic matter and COD measures the oxygen required to decompose organic and inorganic constituents present in the wastewater by chemical reaction. In this paper, OGATA et al. examined the effects of linear velocity and contact time of activated carbon. In this study, the effect of $\mathrm{pH}$ on the adsorption of chlorine from drinking water by activated carbon was also studied. ${ }^{5}$ Martin et al. also conducted researches on the purification of water with activated carbon. ${ }^{6}$ In the study of Shengpin et al., the effect of $\mathrm{pH}$ and calcium ion concentration on the process of adsorption and reduction of activated carbon was studied. ${ }^{7}$ In their research, Wang et al. studied the effect of effluent $\mathrm{pH}$ changes on the elimination of microorganisms, and in this study, Wastewater effluent chloride was removed by activated carbon. ${ }^{8}$

\section{THEORY}

The phenomenon of surface adsorption is divided into physical and chemical forms.
Physical adsorption, or Van der Waals, is a reversible phenomenon that results in gravitational forces between solid molecules and the absorbed material. For example, when the gravitational forces between a solid and a gas are greater than the forces between the gas molecules, the gas accumulates and condenses on the solid surface, even if the gas pressure decreases below the vapor pressure at the same temperature. This compression mode is associated with heat production, which is slightly higher than the latent heat of evaporation $\left(\mathrm{Q}_{\mathrm{V}}\right)$ and is approximately equal to heat of sublimation. The absorbed material does not diffusion (penetrate) the solid crystalline structure and does not dissolve in it, but will remain on the surface. However, if the solid has a large porosity and many tubular capillaries, the absorbed material will penetrate into these gaps if it moistens the solid. Equilibrium pressure is lower for the surface of the concave liquid with a low curvature radius than the large smooth surface, so the adsorption is increased by the same amount. In any case, in the equilibrium partial pressure equilibrium, the absorbed material is in contact with the gas phase pressure, and by reducing the pressure of the gas phase or by increasing the temperature, the absorbed gas is easily excreted and separated from the surface.

Chemical adsorption, or activated adsorption, is the result of solid chemical interactions. The resulting chemical bonding power varies significantly in different states, and it is virtually difficult to identify chemical compounds, but the bonding forces are usually greater than what is present in physical adsorption. The heat released in the adsorption reaction is usually high, and is similar to the heat of a chemical reaction. The process is generally irreversible, and with the chemical separation of the adsorbed material a chemical modification is seen. Physical adsorption may occur in low temperature and at high temperatures chemical adsorption may be seen, and both phenomena may occur at the same time.

Absorbents are usually consumed in the form of granules and their size varies from $12 \mathrm{~mm}$ in diameter to $50 \mu \mathrm{m}$. Solids must have some engineering properties based on application and consumption status. For example, if they are used in a fixed bed with gas or liquid flow, they should not cause much pressure difference and should not be carried out by fluid flow. Important parameters in the selection of activated carbon are given in Table 1. 
Table 1

Important parameters in the selection of industrial adsorbents

\begin{tabular}{c|c}
\hline Unit & Parameter \\
\hline- & Porosity \\
- & Hardness and Resistance to Abrasion \\
$\mathrm{kg} / \mathrm{m}^{3}$ & Density \\
- & Purity \\
- & Degree of Activation \\
$\mathrm{m}^{2} / \mathrm{m}^{3}$ & Specific Surface \\
$\mathrm{gr} / \mathrm{gr}$ & Adsorption Capacity \\
\hline
\end{tabular}

The most important factors in the design of absorption towers are the two most important parameters of linear velocity and contact time. ${ }^{9}$
The relationship between Contact Time and linear velocity is as follows.

$$
\begin{gathered}
\text { Contact time }(\mathrm{min})=\text { Carbon Volume }\left(\mathrm{m}^{3}\right) *(1 \mathrm{hr} / 60 \mathrm{~min}) / \text { Flow Rate }\left(\mathrm{m}^{3} / \mathrm{hr}\right) \\
\text { Linear Velocity }(\mathrm{m} / \mathrm{hr})=\text { Flow Rate }\left(\mathrm{m}^{3} / \mathrm{hr}\right) / \text { Surface area }\left(\mathrm{m}^{2}\right)
\end{gathered}
$$

Usually the residence time of the fluid is between 6 to 30 minutes and the linear velocity of the fluid is between 5 to 20 meters per hour. ${ }^{10}$

In recent studies a lot of adsorption isotherm models involving solid-fluid interface have presented $^{11-13}$ and various models have been proposed for the study of surface adsorption kinetics in filled substrates, which are introduced below.

\section{Thomas Model}

This simple model assumes that the resistance to mass transfer inside the solid and the mass transfer resistance outside the fluid film are negligible. In fact, in this model, the absorption rate is controlled by the surface reaction between the adsorbent and the unused capacity of the adsorbent. In this model, the assumption of the second quasi-reversible velocity equation and the Langmuir isotherm is established.

$$
\ln \left(\frac{C_{F}}{C}-1\right)=\frac{K_{T h} \cdot q_{e} \cdot m}{Q}-K_{T h} \cdot C_{F} \cdot t
$$

where $K_{T h}$ is Thomas rate, $\mathrm{m}$ is absorbent mass in the column, $q_{e}$ is bed adsorption capacity, $\mathrm{C}_{\mathrm{F}}$ is the initial concentration (inlet), $\mathrm{t}$ is the adsorption time, c is secondary concentration (outlet), and Q is the flow rate. ${ }^{14}$ With drawing the linear equation $\ln \left(\frac{C_{F}}{C}-1\right)$ on t, $q_{e}$ and $K_{T h}$ are obtained.

\section{Adams - Bohart model}

This model is also known as BDST (bed depth service time) and is based on the theory of surface reaction speed. Adams and Bohart (1920) began their analysis with the chlorine and charcoal transmission curve. They assumed that the chlorine uptake rate was proportional to the chlorine concentration in the balk fluid and the residual adsorption capacity of the charcoal.

$$
\ln \left(\frac{C_{0}}{C_{t}}-1\right)=\frac{q_{m} \cdot H \cdot K_{b}}{u}-K_{B} \cdot C_{0} \cdot t
$$

where $\mathrm{H}$ is bed length, $\mathrm{t}$ is the adsorption time, $\mathrm{q}_{\mathrm{m}}$ is the maximum adsorption capacity, $\mathrm{u}$ is the fluid velocity, and $K_{B}$ is Bohart - Adams constant.

By plotting $\ln \left(\frac{C_{0}}{C_{t}}-1\right)$ versus $\mathrm{t}, \mathrm{q}_{\mathrm{m}}$ and $K_{B}$ are calculated based on line sleep and intercept. ${ }^{14}$

\section{Yoon - Nelson Model}

In the Yoon-Nelson model, it was assumed that the decrease in the probability of adsorption of any absorbed material is proportional to the probability of its adsorption and progression in the adsorbent. This can be shown as follows:

$$
\ln \left(\frac{C_{t}}{C_{0}-C_{t}}\right)=K_{Y N} \cdot t-t_{1 / 2} K_{Y N}
$$

where $K_{Y N}$ is Yoon - Nelson constant, $\mathrm{t}$ is adsorption time, $t_{1 / 2}$ is the required tie for 
consuming $50 \%$ of adsorption bed, and $C_{0}$ and $C_{t}$ are inlet and outlet adsorbent fluid concentrations, respectively.

By plotting $\ln \left(\frac{C_{t}}{C_{0}-C_{t}}\right)$ versus $\mathrm{t}$, theoretical $K_{Y N}$ and $t_{1 / 2}$ are calculated. Yoon - Nelson model is not only a simpler form compared to other models, but also it doesn't need details about material and adsorbent characteristics. ${ }^{14}$

\section{Wang Model}

Wang et al. developed a mass transfer model in 2003. This model has been used to describe the progression curve of $\mathrm{Co}$ and $\mathrm{Zn}$ ion adsorption in the fixed bed.

$$
x=C_{t} / C_{0} t=t_{1 / 2}-\frac{1}{K_{w}} \ln \left(\frac{1}{1-x}\right)
$$

where $K_{w}$ is Wang kinetic constant, t is adsorption time, $t_{1 / 2}$ is the required tie for consuming $50 \%$ of adsorption bed, and $C_{0}$ and $C_{t}$ are inlet and outlet adsorbent fluid concentrations, respectively.

By plotting $\ln \left(\frac{C_{t}}{C_{0}}-1\right)$ versus $\mathrm{t}$, the slope and interception give $K_{w}$ and, $t_{1 / 2}$ respectively. ${ }^{15}$

\section{Wolborska model}

Wolborska et al. analyzed the p-nitrophenol absorption in activated carbon and found that the initial part of the progression curve was driven by the release of the film with a constant kinetic coefficient and the concentration profile of the primary control axis in the adsorption column at a constant velocity. In addition, the width of the concentration profile in the column and the final progress curve have been almost constant. Based on the above observations, they developed a model to describe progress in a low concentration area, which is as follows:

$$
\ln \left(\frac{C_{t}}{C_{0}}\right)=\frac{\beta_{L} \cdot C_{0} \cdot \varepsilon}{\rho \cdot q_{F}} t-\frac{\beta_{L} \cdot H}{u}
$$

By plotting $\ln \left(\frac{C_{t}}{C_{0}}\right)$ versus t, $q_{F}$ and $\beta_{L}$ are calculated based on line slope and interception, respectively. ${ }^{15}$

\section{EXPERIMENTAL}

\section{Materials and Equipment}

The specifications of the activated carbon used in the study are shown in Table 2.

In this study, $4.5 \mathrm{~kg}$ (9 liters) of activated carbon made by PICA Company was used. And this adsorbent is located in a leading tower of fixed bed. The specifications of the fixed bed pilot tower used for the tests are shown in Table 3.

Table 2

Activated carbon specifications used in this study

\begin{tabular}{c|c|c|c}
\hline unit & The original designer & PICA & property \\
\hline $\mathrm{mm}$ & Coconut shell Carbon, Ash Free & -- & Structure \\
$\mathrm{mm}$ & $104 \sim 2.05$ & $1018 \sim 2.36$ & Mesh Size \\
$\mathrm{kg} / \mathrm{m}^{3}$ & $480 \sim 520$ & $480 \sim 520$ & Bulk Density \\
$\mathrm{m}^{2} / \mathrm{gr}$ & $1000 \sim 1050$ & $>900$ & Total Surface Area \\
\hline
\end{tabular}

Table 3

Specifications of Pilot Tower Activated Carbon Test

Dechlorination Carbon Tower

Service: to Remove Free Chlorine from Cooling Water

\begin{tabular}{c|c|c}
\hline $\mathrm{m}^{3} / \mathrm{h}$ & 0.300 & Flow rate \\
$\mathrm{C}^{\circ}$ & 35.00 & Operating Temperature \\
$\mathrm{m}^{3}$ & 0.020 & Geometric Capacity \\
$\mathrm{mm}$ & 106.0 & Diameter \\
$\mathrm{mm}$ & 1133 & Height of Bed \\
$\mathrm{mm}$ & 2400 & Height of Tower \\
\hline
\end{tabular}




\section{Test Method}

In this study, titration method was used to accurately measure the amount of free chlorine in cooling water. In this procedure, $200 \mathrm{~mL}$ of the sample was transferred to Erlenmeyer through Graduated cylinders. $0.5 \mathrm{~mL}$ of hydrochloric acid $(\mathrm{HCl})$ was added to the sample by pipette. The solution inside Erlenmeyer was titrated with methyl orange uranium until it reached pink color. Method of calculating titration:

$\mathrm{F} \mathrm{Cl}_{2} \mathrm{ppm}=\mathrm{V} \times 0.5, \mathrm{~V}=$ Methyl Orange intake for titration

\section{RESULTS AND DISCUSSION}

Experiments were performed to remove chlorine by a fixed bed filled with activated carbon for 14 days. About 51549 liters of chlorinated water in different concentrations and $\mathrm{pH}$ values were passed through the bed of leading Tower and by controlling and recording the flow of chlorinated water; $\mathrm{pH}$ tests; The values of free chlorine inlet and outlet of leading tower were measured. The results are shown in Table 4.

Table 4

Experimental results of free chlorine removal from water by activated carbon

\begin{tabular}{|c|c|c|c|c|}
\hline $\begin{array}{l}\text { Free chlorine adsorbed } \\
(\mathrm{gr} / \mathrm{hr})\end{array}$ & $\begin{array}{l}\text { Free chlorine content inlet } \\
\text { (ppm) }\end{array}$ & $\begin{array}{l}\text { Flow } \\
(\mathrm{L} / \mathrm{hr})\end{array}$ & $\mathrm{pH}$ & $\begin{array}{c}\text { Time in Operation } \\
(\mathrm{hr})\end{array}$ \\
\hline 7.30 & 28.4 & 257 & 5.0 & 1 \\
\hline 10.6 & 35.5 & 300 & 4.9 & 1 \\
\hline 11.9 & 39.6 & 305 & 5.0 & 2 \\
\hline 6.75 & 35.5 & 190 & 5.1 & 2 \\
\hline 14.7 & 53.0 & 278 & 5.0 & 2 \\
\hline 8.43 & 42.6 & 198 & 4.8 & 2 \\
\hline 7.45 & 35.5 & 210 & 5.0 & 2 \\
\hline 7.10 & 28.4 & 250 & 5.0 & 2 \\
\hline 9.94 & 35.5 & 280 & 4.0 & 2 \\
\hline 4.90 & 21.3 & 230 & 4.1 & 2 \\
\hline 7.40 & 30.2 & 245 & 3.9 & 2 \\
\hline 10.6 & 35.5 & 300 & 4.1 & 2 \\
\hline 6.15 & 35.5 & 300 & 7.5 & 2 \\
\hline 11.4 & 35.5 & 320 & 4.0 & 2 \\
\hline 6.71 & 35.5 & 220 & 7.0 & 4 \\
\hline 14.8 & 53.0 & 240 & 3.9 & 6 \\
\hline 7.36 & 32.0 & 230 & 3.5 & 8 \\
\hline 8.52 & 42.6 & 200 & 3.5 & 6 \\
\hline 4.50 & 30.0 & 150 & 3.5 & 12 \\
\hline 6.04 & 35.5 & 170 & 5.0 & 8 \\
\hline 3.13 & 21.3 & 155 & 5.1 & 6 \\
\hline 4.50 & 30.0 & 150 & 5.0 & 10 \\
\hline 2.50 & 25.0 & 100 & 5.0 & 8 \\
\hline 1.82 & 28.2 & 100 & 8.5 & 6 \\
\hline 5.40 & 30.0 & 180 & 5.0 & 10 \\
\hline 3.20 & 20.0 & 160 & 6.0 & 8 \\
\hline 4.55 & 60.3 & 150 & 8.0 & 6 \\
\hline 9.52 & 63.5 & 150 & 6.0 & 10 \\
\hline 7.82 & 46.0 & 170 & 6.0 & 8 \\
\hline 4.16 & 32.0 & 130 & 6.0 & 8 \\
\hline 8.05 & 35.0 & 230 & 6.0 & 8 \\
\hline 5.46 & 24.8 & 220 & 4.5 & 8 \\
\hline 9.58 & 53.2 & 180 & 4.6 & 8 \\
\hline 9.94 & 35.5 & 280 & 4.5 & 8 \\
\hline 4.69 & 21.3 & 220 & 5.0 & 8 \\
\hline 4.24 & 42.6 & 130 & 7.8 & 8 \\
\hline 8.16 & 81.6 & 100 & 5.0 & 8 \\
\hline 4.36 & 43.6 & 100 & 6.0 & 8 \\
\hline 4.97 & 49.7 & 100 & 6.0 & 8 \\
\hline 3.94 & 35.8 & 110 & 6.0 & 8 \\
\hline 5.00 & 50.0 & 100 & 6.5 & 8 \\
\hline 4.20 & 42.0 & 100 & 6.8 & 8 \\
\hline 3.90 & 35.5 & 110 & 6.5 & 8 \\
\hline 7.71 & 70.1 & 110 & 6.5 & 8 \\
\hline 4.79 & 53.2 & 90 & 5.0 & 8 \\
\hline 4.26 & 42.6 & 100 & 5.0 & 8 \\
\hline 10.1 & 78.1 & 130 & 3.0 & 8 \\
\hline
\end{tabular}


Table 4 (continued)

\begin{tabular}{c|c|c|c|c}
\hline 34.1 & 213 & 160 & 3.0 & \\
7.84 & 60.3 & 130 & 3.0 & 8 \\
21.4 & 214 & 100 & 4.0 & 8 \\
132 & 1200 & 110 & 4.5 & \\
119 & 1080 & 110 & 4.6 & 8 \\
126 & 1180 & 110 & 5.5 & 1 \\
97.8 & 1020 & 110 & 7.0 & 1 \\
202 & 962 & 280 & 7.0 & 1 \\
59.4 & 1020 & 110 & 7.2 & 1 \\
42.2 & 982 & 120 & 8.0 & 1 \\
30.4 & 1060 & 110 & 9.0 & 1 \\
0.66 & 986 & 110 & 10 & \\
\hline
\end{tabular}

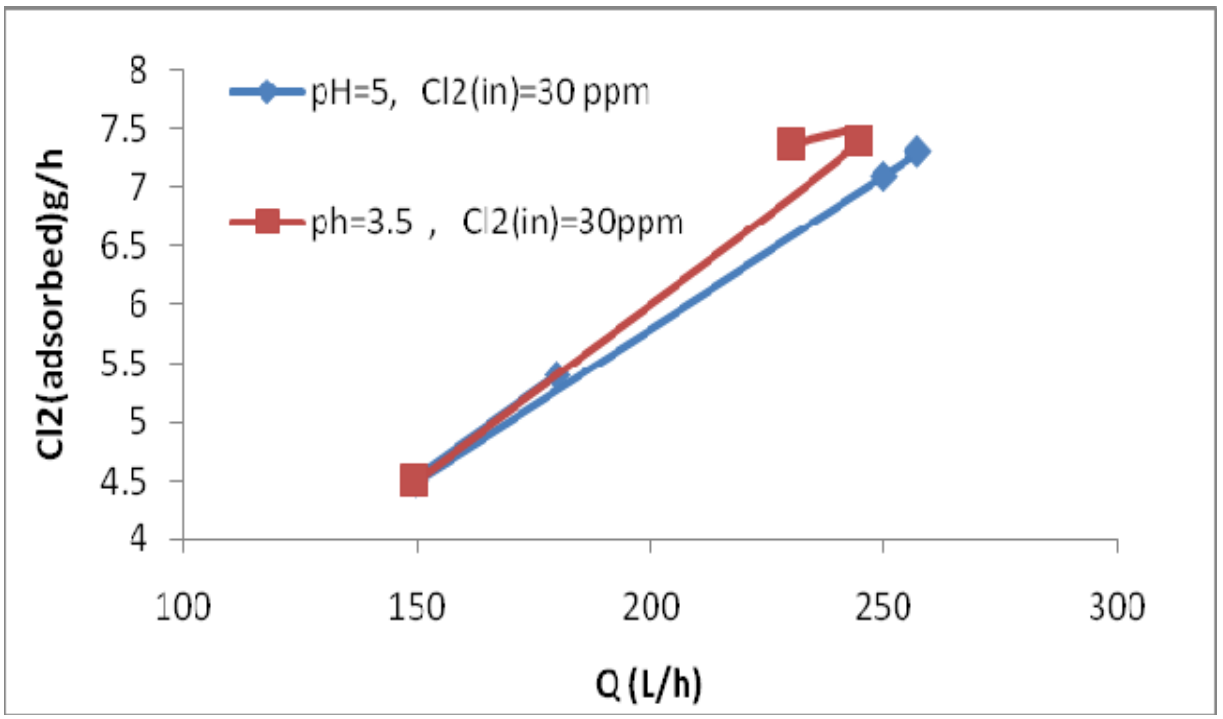

Fig. 1 - The amount of free chlorine uptake by activated carbon in different discharges and $\mathrm{pHs}$ at chlorine input concentrations equal to $30 \mathrm{ppm}$.

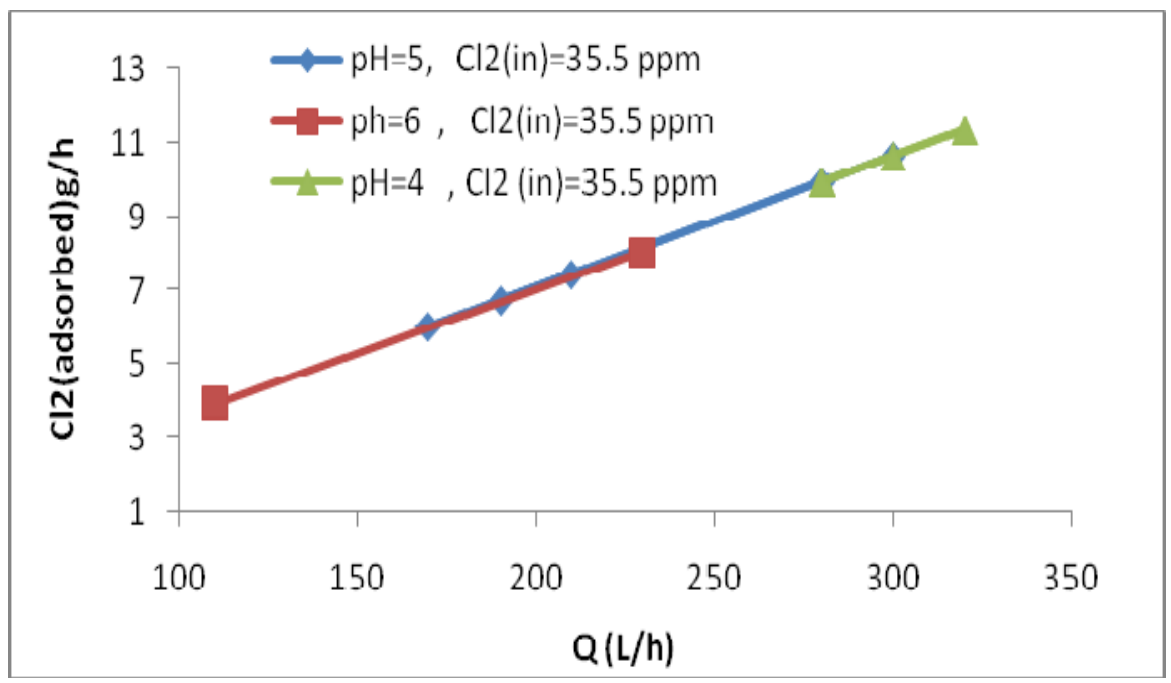

Fig. 2 - The amount of free chlorine uptake by activated carbon in different flow and $\mathrm{pH}$ values at the chlorine inlet concentration of $35.5 \mathrm{ppm}$.

The effect of flow on free chlorine uptake by activated carbon is shown in Figures 1 to 3. As can be seen, the free chlorine input concentrations vary and at different $\mathrm{pH}$ values, the rate of free chlorine uptake by activated carbon increases with increasing flow rate.

In Figure 2 the flow rate for different $\mathrm{pH}$ are not the same. 


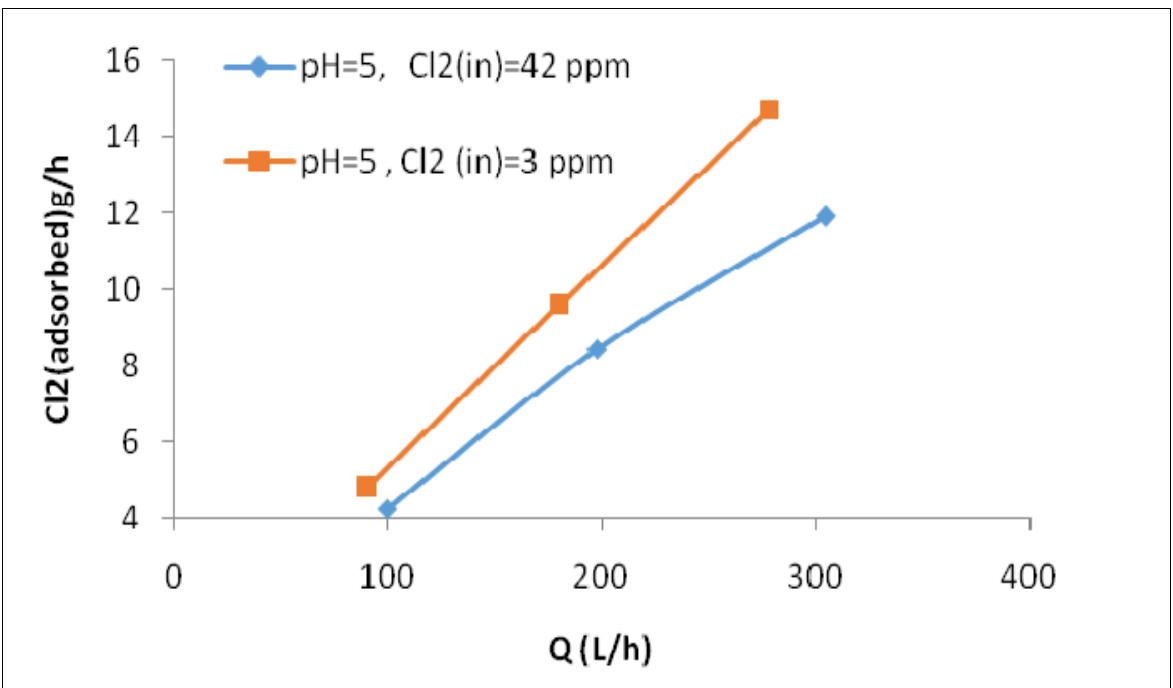

Fig. 3 - The amount of free chlorine uptake by activated carbon in different flow and $\mathrm{pH}$ values at chlorine input concentrations.

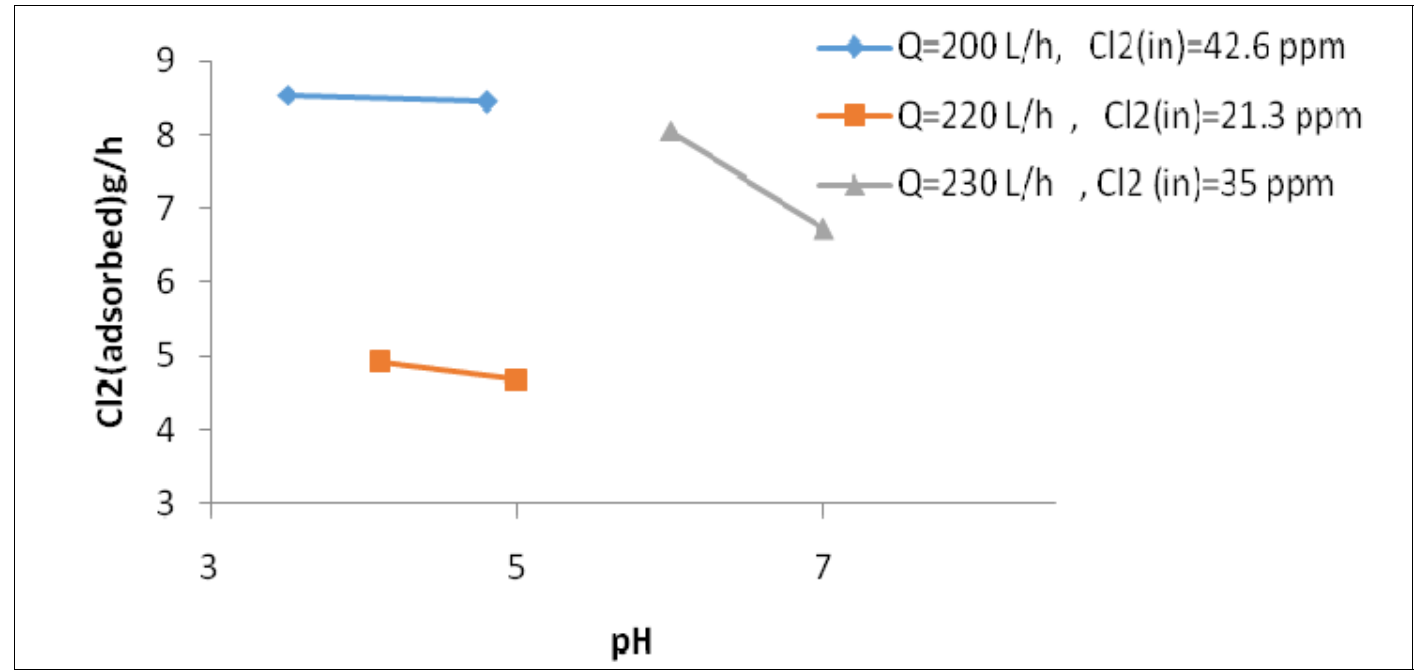

Fig. 4 - Changes in the amount of free chlorine uptake by activated carbon at different $\mathrm{pH}$ levels.

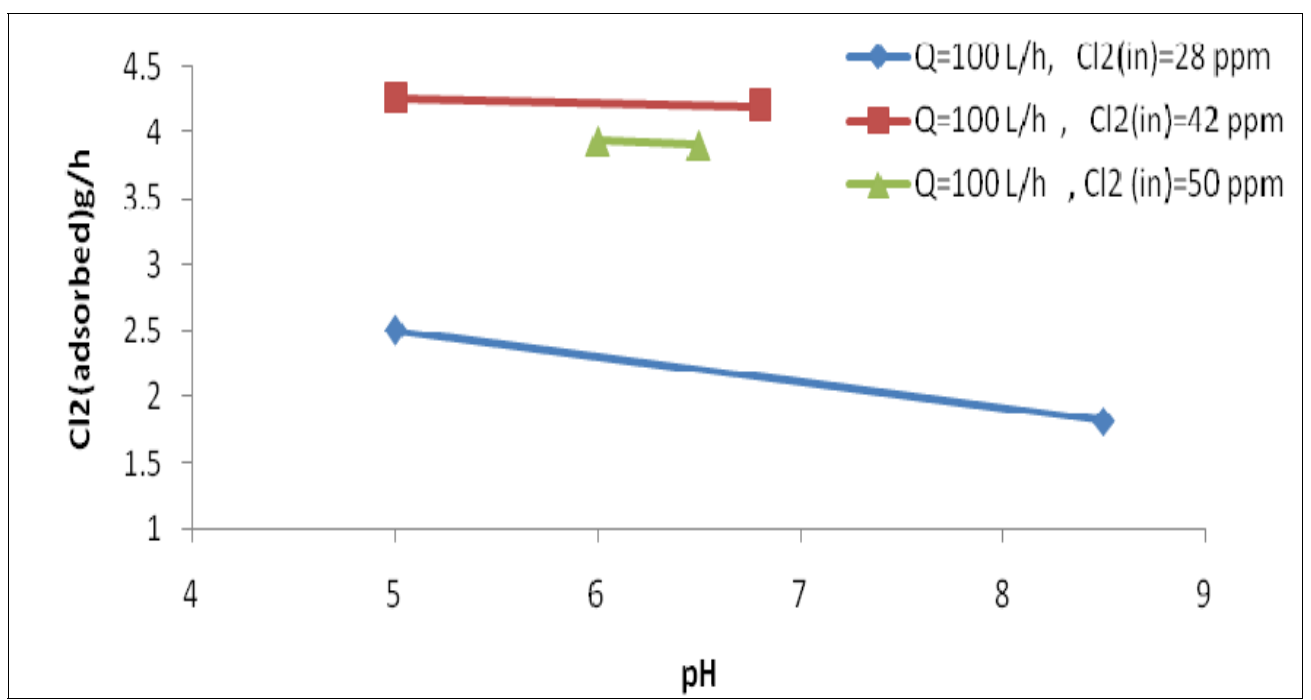

Fig. 5 - Changes in free chlorine uptake by activated carbon at different $\mathrm{pH}$ rates in flow of 100 liters per hour. 


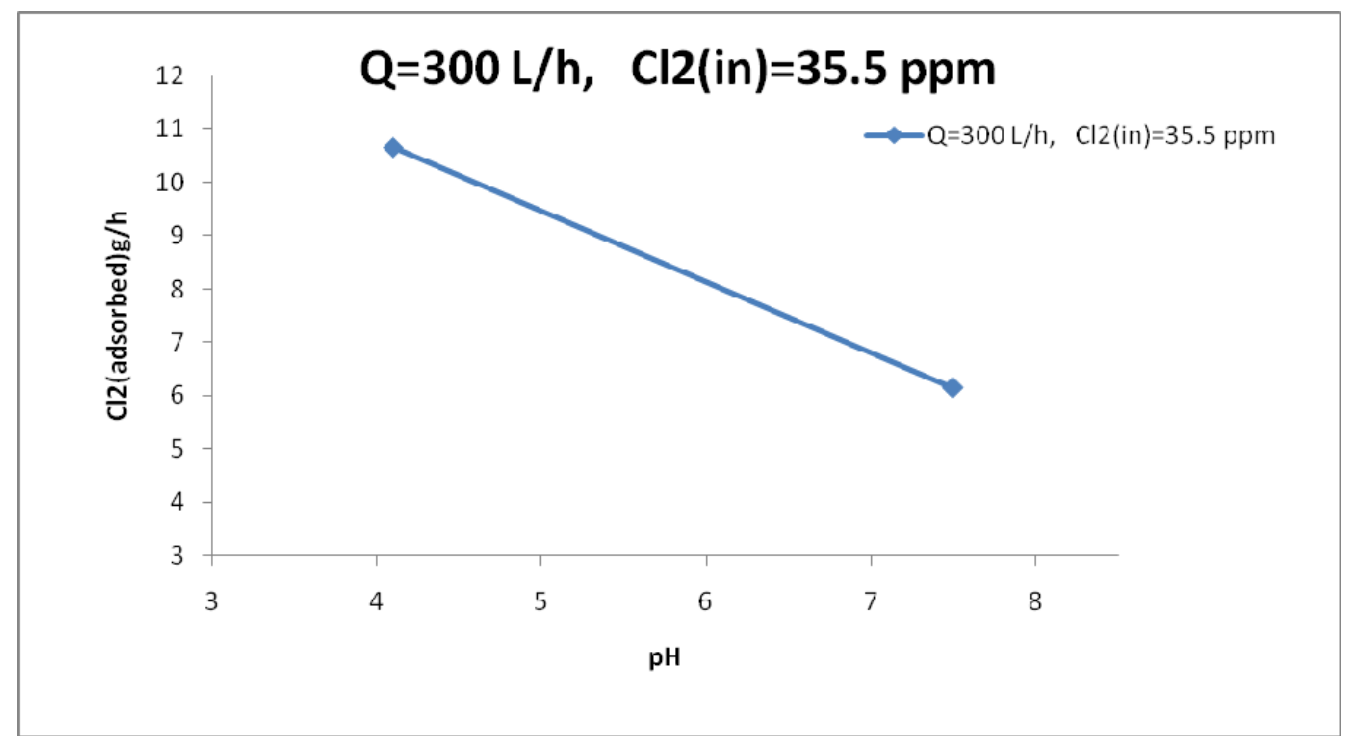

Fig. 6 - Changes in free chlorine uptake by activated carbon at different $\mathrm{pH}$ levels in flow of 300 liters per hour.

The effect of $\mathrm{pH}$ on free chlorine uptake by activated carbon is shown in Figures 4 to 6 . As can be seen, in the inlet concentrations of free chlorine, and in different flow values, by increasing the $\mathrm{pH}$, the absorption of free chlorine by activated carbon decreases.

\section{Kinetic study of free chlorine absorption by activated carbon adsorbent}

In this study, various models for the kinetics of free chlorine adsorption in the fixed bed have been investigated.

With plotting linear equation of $\ln \left(\frac{C_{F}}{C}-1\right)$ versus $\mathrm{t}$, experimental kinetic values of Thomas constant $K_{T h}$ and maximum adsorption $q_{e}$ were obtained. Figure 7 shows the graphical method of determining kinetic parameters of Thomas model.

With respect to calculations, the amount of Thomas constant $K_{T h}=0.02037037 \mathrm{~min}^{-1}$ and adsorption bed capacity $\mathrm{q}_{\mathrm{e}}=123.8836$.

By plotting the linear equation $\ln \left(\frac{C_{0}}{C_{t}}-1\right)$ versus time, the experimental kinetic values of Bohart - Adams $K_{B}$ and maximum adsorption bed capacity were calculated based on slope and interception. Figure (8) shows the graphical method of determining the kinetic parameters of the Adams Bohart model. It should be noted that in the calculations the bed height $\mathrm{H}=1133 \mathrm{~mm}$ is considered.

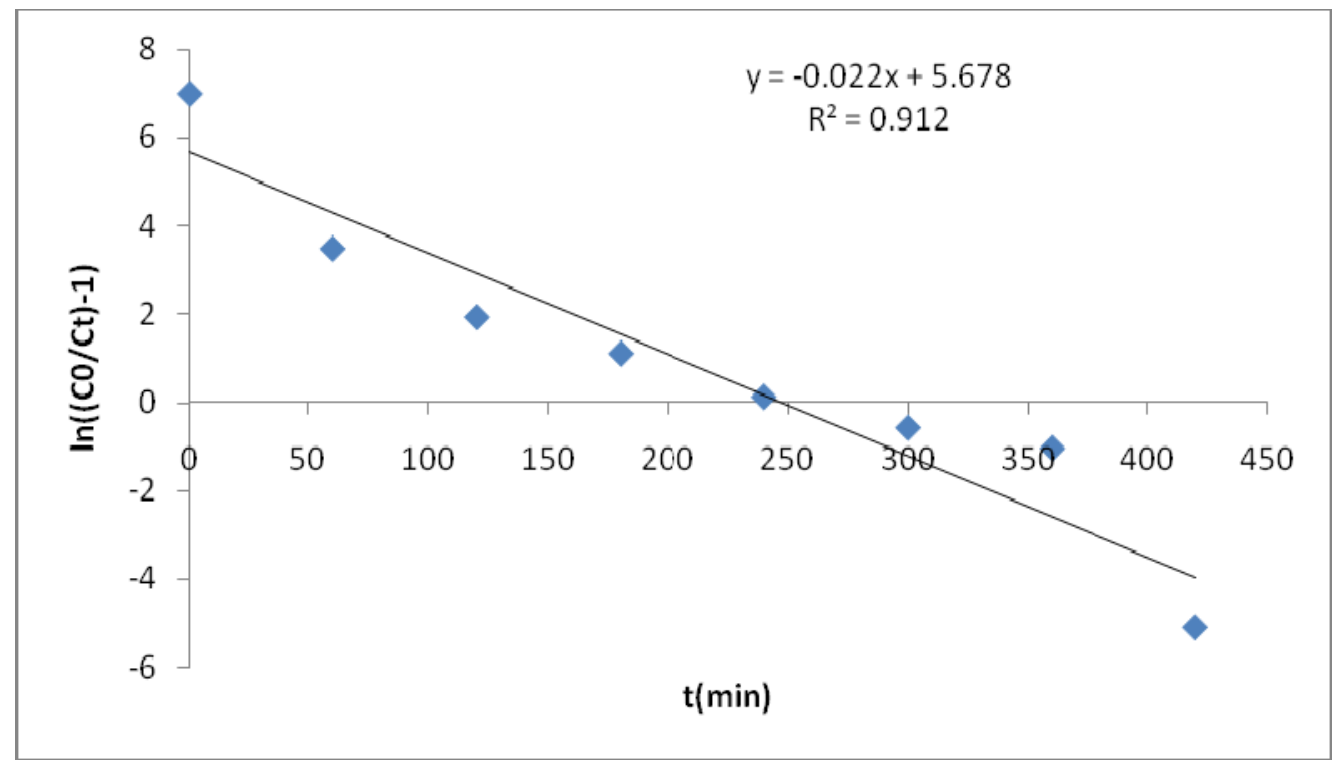

Fig. 7 - Plotting the changes of $\ln \left(\frac{C_{F}}{C}-1\right)$ versus time for determining kinetic constants of Thomas model. 


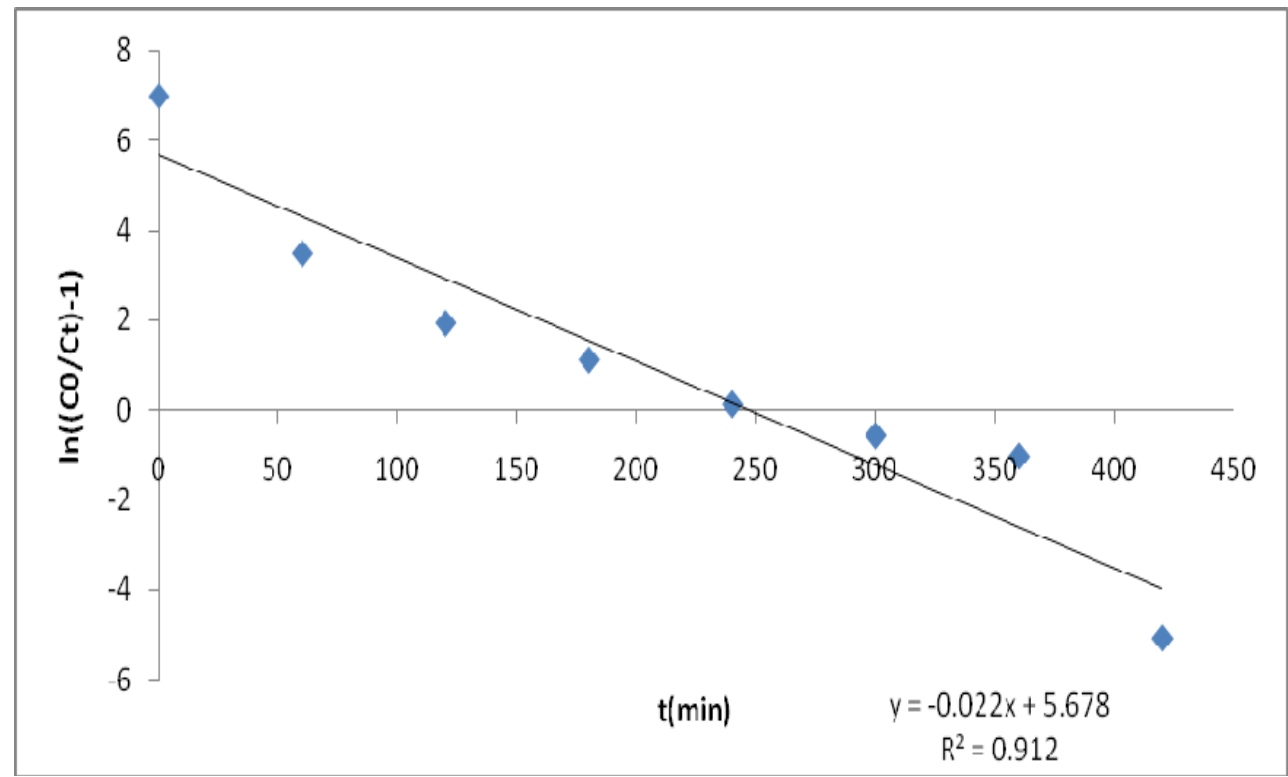

Fig. 8 - The plot of $\ln \left(\frac{C_{0}}{C_{t}}-1\right)$ changes with respect to time in order to determine the kinetic constants of Bohart - Adams model.

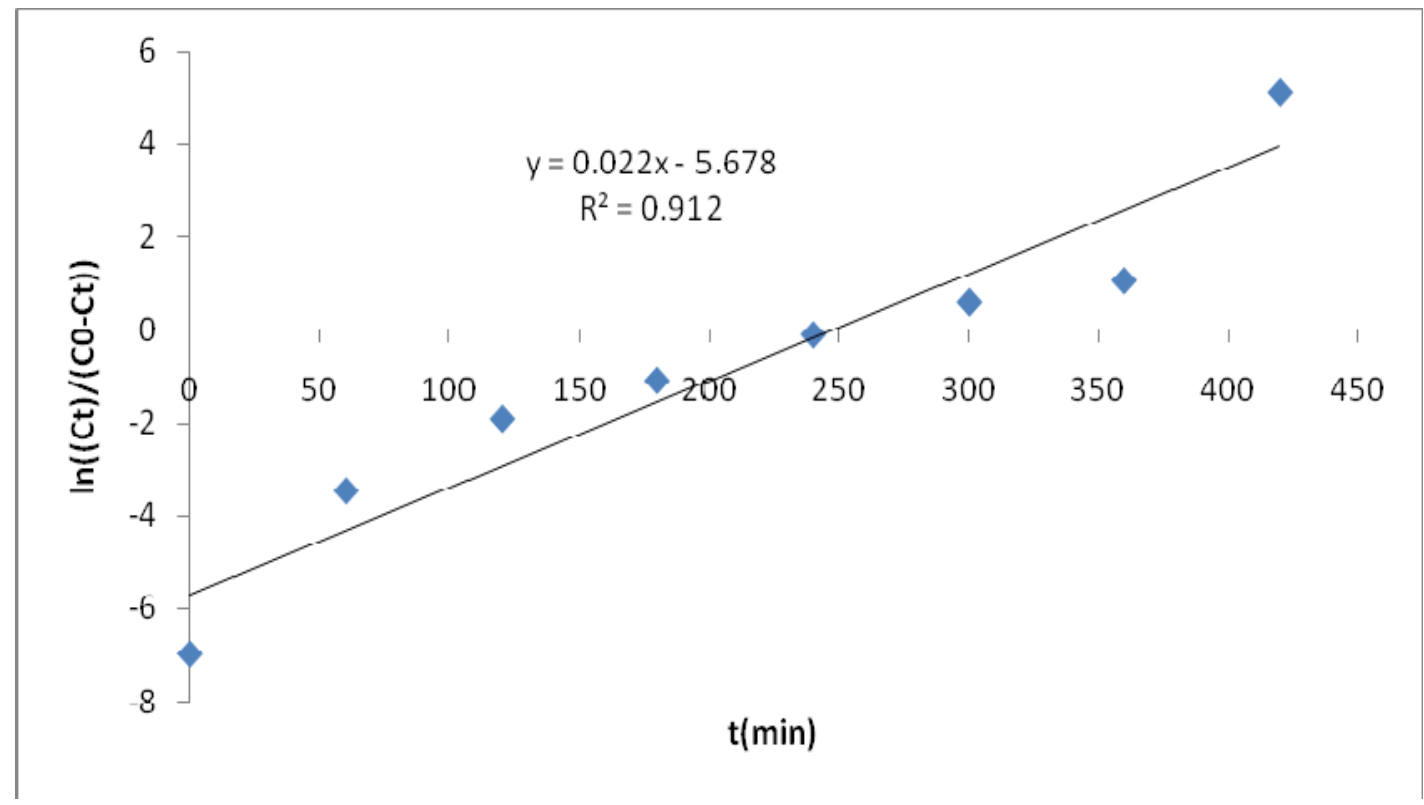

Fig. 9 - The plot of $\ln \left(\frac{C_{t}}{C_{0}-C_{t}}\right)$ changes versus $t$ for determination of kinetic constants of Yoon - Nelson model.

With respect to the calculations, the amount of Bohart Adams constant were $K_{\mathrm{B}}=0.02037037 \mathrm{~min}^{-1}$ and the maximum adsorption capacity of bed $\mathrm{q}_{\mathrm{m}}=511.307$.

By plotting the linear equation $\ln \left(\frac{C_{t}}{C_{0}-C_{t}}\right)$ versus time, the amounts of experimental kinetic constant of Yoon Nelson $K_{Y N}$ and $t_{1 / 2}$ were obtained based on the slope and interception, respectively. Figure (9) shows the graphical method for determining kinetic parameters of Yoon - Nelson model.
With respect to the calculations of constant value of Yoon - Nelson $K_{Y N}=0.022 \mathrm{~min}^{-1}$, the required time for consuming $50 \%$ of adsorption bed was $t^{1 / 2}=258.09 \mathrm{~min}$.

By plotting the linear equation $\ln \left(\frac{C_{0}}{C_{t}}-1\right)$ versus time, the experimental kinetic values of Wang constant $K_{w}$ and $t_{1 / 2}$ were calculated based on the slope and interception, respectively. Figure (10) shows the graphical method for determining kinetic parameters of Wang model. 


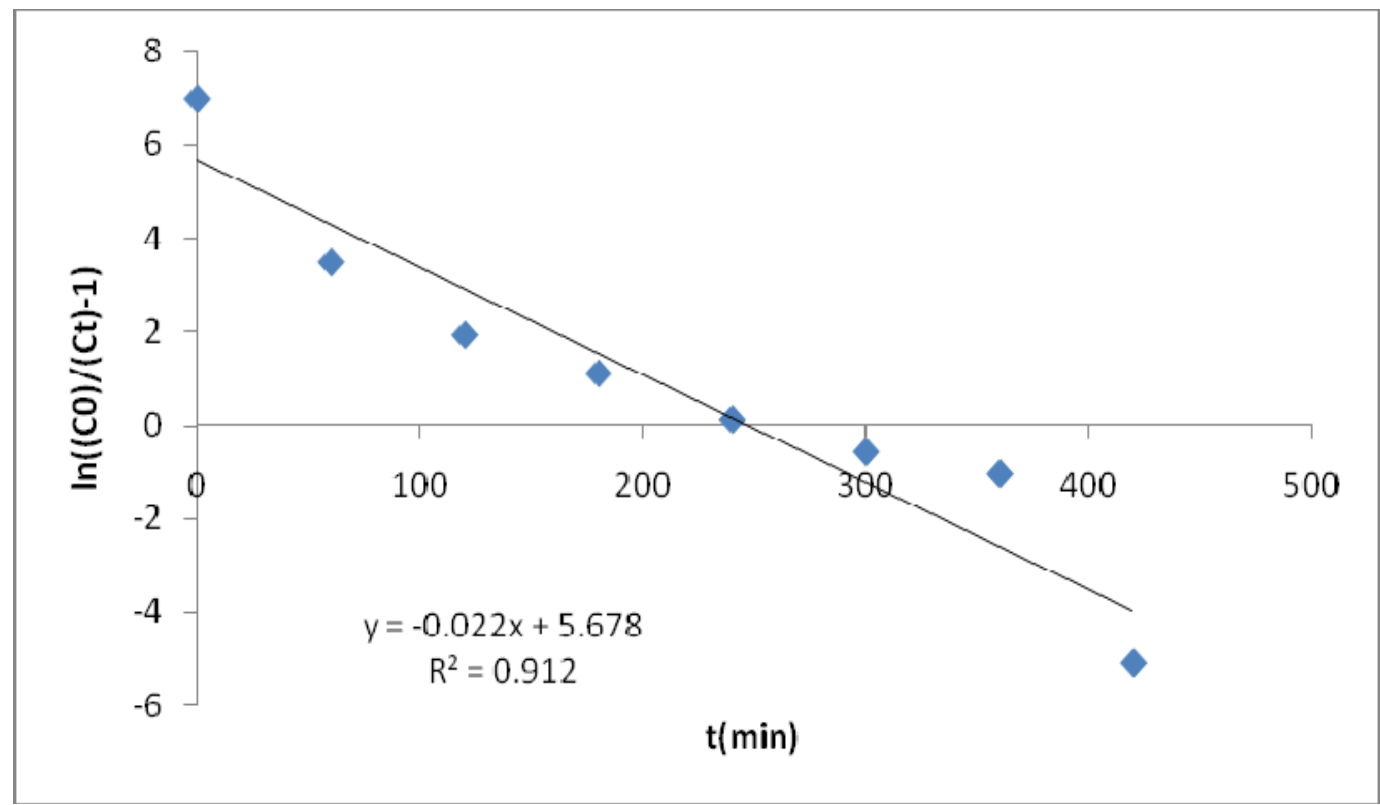

Fig. 10 - Plotting the changes of $\ln \left(\frac{C_{0}}{C_{t}}-1\right)$ versus time for determining kinetic constants of Wang model.

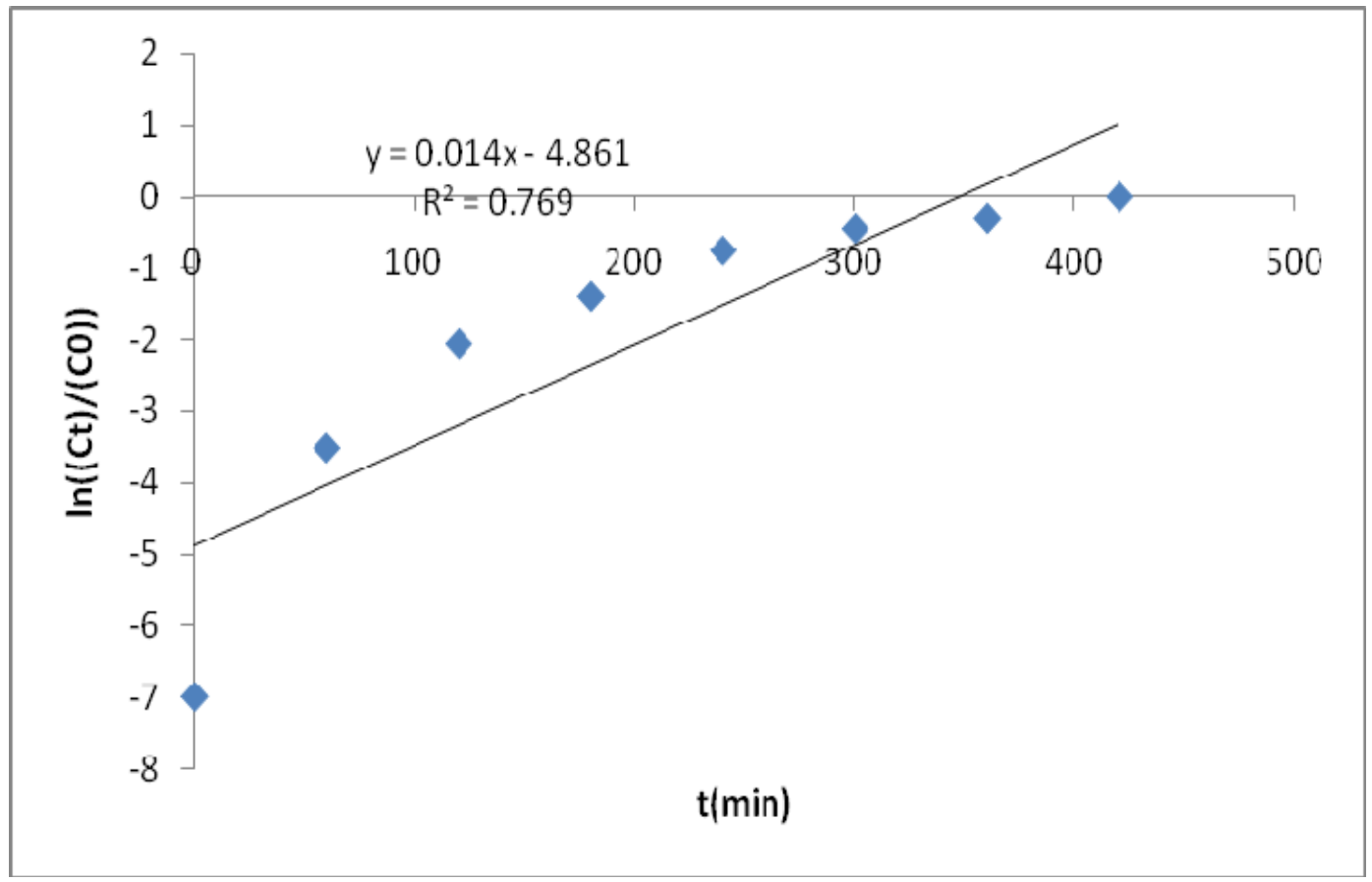

Fig. 11 - Plotting the changes of $\ln \left(\frac{C_{t}}{C_{0}}\right)$ versus t for determination of Wolborska model's kinetic parameters.

With respect to calculations of Wang constant $K_{W}=0.022$ $\min ^{-1}$ and the required time for consuming $50 \%$ adsorption bed $t^{1 / 2}=258.09$ min was obtained.

By plotting the linear equation of $\ln \left(\frac{C_{t}}{C_{0}}\right)$ versus time, the experimental kinetic values of Wolborska model $\beta_{L}$ and maximum capacity of adsorption bed $q_{F}$ were calculated based on slope and interception, respectively. Figure (11) shows the graphical method for determination of Wolborska model's kinetic parameters. It is necessary to mention that in the calculations of bed height model, $\mathrm{H}=1133 \mathrm{~mm}$ and bed porosity $\varepsilon=0.38$, and bed density $\rho=500 \mathrm{~kg} / \mathrm{m}^{3}$ were considered. 
With respect to the calculations, the amount of Wolborska model's constant $\beta_{L}=53.506 \mathrm{~min}^{-1}$ and maximum bed adsorption $q_{F}=272$ were obtained.

\section{CONCLUSIONS}

In this study, the removal of free chlorine from the circulating water of the cooling tower was examined by activated carbon. The results show that the absorption of chlorine in acidic environment ( $\mathrm{pH}$ range 1 to 4 ) has been very high compared to the game environment. also by examining different models, the kinetic constant of velocity was calculated, in Thomas, AdamsBohart Models $K_{b}=K_{T h}=0.02037037 \mathrm{~min}^{-1}$ $\left(\mathrm{R}^{2}=0.915\right)$, and in models of Wang and Yoon Nelson, $\mathrm{K}_{\mathrm{W}}=K_{Y N}=0.022 \mathrm{~min}^{-1}$ was obtained and the time required to consume $50 \%$ of the adsorption bed was $t^{1 / 2}=258.09 \mathrm{~min}$.

\section{REFERENCES}

1. Y. Siong, J. Idris and M. Atabaki, Water Resources, 2013, $135,1-19$.
2. L. Chen, A. Pinto and A. N. Alshawabkeh Catalysts, 2019, 9, 601-617

3. B. Rajaeian, S. Allard, C. Joll and A. Heitz, Water Research, 2018, 138, 152-159.

4. S. Lakshmanan and Y. L. Yung, Blue Green Systems, 2019, 1, 72-85.

5. F. Ogata, H. Tominaga, A. Ueda, Y. Tanaka, Y. Lwata and N. Kawasaki, J. Oleo Sci., 2013, 241-244.

6. M. J. Sweetman, S. May, N. Mebberson, P. Pendleton, K. Vasilev, S. E. Plush and J. D. Hayball, J. Carbon Research, 2017, 3, 18-22.

7. S. Li, W. Li' H. Chen, F. Liu, S. Jin, X. Yin, Y. Zheng and B.Liu, RSC Adv., 2018, 8, 16834-16841.

8. C. Wang, Z. Ying, M. Ma, M. X. Huo and W. Yang, Water, 2019, 11, 2639-2611.

9. M. Y. Abdul - Ahad, Iraqi J. Chem. Petroleum Eng., 2008, 9, 41-49.

10. F. Çeçen and O. Aktas, "Activated Carbon for Water and Wastewater Treatment Integration of Adsorption and Biological Treatment", Wiley-VCH, 2011.

11. S. G. Muntean, G. Simu, P. Sfarloaga and C. Bologa, Rev. Chim. (Bucharest), 2010, 61, 70-73.

12. J. U. K. Oubagaranadin, Z. V. P. Murthy and P. S. Rao, Indian Chem. Eng., 2007, 49, 196-204.

13. B. B. Mohammed, K. Yamni, N. Tijani and H. Lgaz, J. Molec. Liquids, 2019, 296, 111997-111102.

14. Z. Xu, J. Cai and B. Pan, J. Zhejiang Univ. Sci. A., 2013, $14,155-176$

15. M. A. Abuh, G. K, Akpomie, N. K, Nwagbara, N. AbiaBassey, D. I. Ape and B. U. Ayabie, Int. J. Basic Appl. Sci., 2013, $l, 800-809$. 
